\title{
The Global Fund at five: what next for universal access for HIV/AIDS, TB and malaria?
}

\author{
Michel Sidibe ${ }^{1} \quad$ Ilavenil Ramiah² Kent Buse $^{3}$
}

J R Soc Med 2006;99:497-500

This is the second in a series of articles on leadership in international health.

In 2001 the G8 committed to the creation of the Global Fund to fight AIDS, Tuberculosis and Malaria (the Global Fund) as an independent financing agency to attract, manage and disburse funds from a wide range of donors, including bilateral, multilateral and private sector organizations. With its focused financial appeal for the three diseases which account for over 6 million deaths per year and widespread political support, the Global Fund in its first five years has raised and disbursed an unprecedented volume of resources. ${ }^{1}$ Its ability to make grants in nearly all developing countries, its operational capacity to move swiftly and transparently in approving project proposals, its direct involvement with civil society, and continuing capacity for critical introspection have led to impressive successes at the country level between 2001-2006. ${ }^{2}$ As many had hoped at its inception, the Global Fund has become one of the most potent weapons to halt HIV, tuberculosis and malaria among the world's most marginalized populations.

Yet, at the end of five years, both the Global Fund as well as many of us who have keenly followed its progress are aware that this organization stands at a critical juncture, facing important questions over its future directions. Some of these concerns arise from lessons learnt from the Global Fund's past experience. Others are catalyzed by the pressures imposed and opportunities provided by the evolving global health environment.

The most important of these opportunities is the country level commitment world over to move towards universal access for prevention, treatment and care for HIV prevention, treatment and care. Proposed access to treatment for AIDS was contested as late as 2002, at the launch of the World Health Organization's (WHO) ' 3 by 5 ' initiative. At the beginning of this year, thousands of people across the world, from all walks of life, argued for universal access to HIV prevention, treatment and care. ${ }^{3}$ This sea change in attitudes has brought the AIDS response to a

\footnotetext{
'Director for Country and Regional Support at UNAIDS, Geneva, Switzerland; ${ }^{2}$ Adviser to the Director for Country and Regional Support at UNAIDS, Geneva, Swizerland; ${ }^{3}$ Research Fellow, Overseas Development Institute, London, UK

Correspondence to: K Buse

E-mail: k.buse@odi.org.uk
}

unique historical juncture. Exceptionally, multiple elements necessary for effective scaling-up, including political commitment, broad-based societal involvement, and advanced knowledge of the epidemiological and sociological pathways of the disease, stand primed for action.

All eyes are now focused on the leadership and support the Global Fund will provide to drive forward the universal access agenda. Beyond the obvious and important potential role of providing predictable and sustainable financing, the Global Fund has the capacity to respond rapidly to country needs to accelerate the pace of action and results in countries. Its response will also be able to sustain broadbased and inclusive, country level involvement. Both features fulfill key recommendations arising from the Universal Access country and regional consultations. ${ }^{4}$ Yet, to fully realize these roles, the Global Fund will need to address four key questions.

\section{FULFILLING ITS CORE MANDATE: RAISING MULTIPLE SUSTAINABLE STREAMS OF FUNDS?}

Sustainable funding is not a distant problem for the Global Fund. According to Roll Back Malaria, Stop TB and UNAIDS, total financial needs to fight the three diseases are estimated to be approximately US $\$ 45$ billion for the biennium 2006-2007. ${ }^{5}$ However, as shown in table 1, the Global Fund has difficulties even in meeting the more modest resource requirements derived from historic levels of new grant approvals and renewals.

The Global Fund needs to carefully and creatively reconsider its strategy in mobilizing sustainable sources of funding. Some of this thinking is already being done, as efforts to leverage new, private finance through innovative partnerships, such as the Product Red campaign, reveal. ${ }^{6}$ More of this out of the box thinking on drawing in a range of new sources of income is crucial. Beyond cash contributions, the private sector should be encouraged to provide services in kind to the Global Fund, for example environmental risk assessments, costing forecasts, logistic and IT support. Equally pertinent are observations that the movement of the Global Fund funds generates considerable profit for the private, international banking sector. The Global Fund must actively negotiate with these banks to reduce fees or to ensure that some of these profits are 


\begin{tabular}{lccc}
\hline & $\mathbf{2 0 0 6}$ & $\mathbf{2 0 0 7}$ & 2006\&2007 \\
\hline $\begin{array}{l}\text { Estimated Grant Approvals: } \\
\text { Renewal of Grants for Phase 2 }\end{array}$ & 1.7 & 1.4 & 3.1 \\
New Round: & & & \\
Programs reapplying after Phase 2 & 0.1 & 0.3 & \\
New Programs & 1.0 & 1.0 & \\
New Rounds & 1.1 & 1.3 & 2.4 \\
& 2.8 & 2.7 & 5.5 \\
Total Approved Needs & 1.9 & 1.5 & 3.4 \\
Less: Pledged to date (31st May, 2006) & 0.9 & 1.2 & 2.1 \\
Additional Pledges Needed & & & \\
\hline
\end{tabular}

Source: Global Fund, Funding the Global Fight Against HIV/AIDS, Tuberculosis and Malaria, Resource Needs for the Global Fund 2006-2007, 2008-2009, June 2006, p. 12

contributed to the Global Fund, simultaneously investigating the greater involvement of country level banks as an alternative option.

Developing country governments and civil society will also need to become more vigorously involved in the process of raising funds. The Global Fund must lobby countries more actively to contribute more funds, either indirectly by reducing import taxes on the Global Fund project related commodities, or directly by contributing part of these duties to the Global Fund. The Global Fund should also work to persuade creditors and debtors to rally behind the Global Fund Debt Conversion concept. ${ }^{7}$ Countries ought to be encouraged by the Global Fund to quickly identify activities and line items related to the three diseases that can be financed from funds available from debt conversion and to include them into their respective budgets so that the Global Fund is able to assess resource requirements from other sources more accurately.

The Global Fund must further seek to create proactive, public demand for the money it raises. Presently, the countries remain at the receiving end, with the Global Fund negotiating with donors on their behalf. Countries however need to be a part of this negotiation, pressing donors to commit more funds. As the bilateral donors question the substantial transaction costs of their individual activities at the country level, the strong presence of countries at that negotiating table with the Global Fund should make the task of raising money and having more bilateral resources channeled through the Global Fund significantly easier.

\section{SHOULD THE GLOBAL FUND EXPEND ITS ENERGIES MORE BROADLY IN PROVIDING TECHNICAL ASSISTANCE TO COUNTRIES?}

At its inception, given the proliferation of implementing agencies at the country level, the Global Fund opted for a lean and nimble operational base. And in the past five years, much of its success in speedy allocation and disbursement of financial resources has been widely attributed to this decision to stay out of implementation. However, those within the Global Fund as well as many in the recipient countries, have come to realize that there is a flipside to speed; countries will need to find technical assistance for developing and implement the Global Fund grants on their own, something many have discovered is not an easy task.

The capacity of many traditional technical providers is not equal to the scale of financial resources now available for operations. The complexity of technical assistance has also increased, involving political advocacy and negotiations to remove bottlenecks in countries. In recognition of these facts, agencies such as UNAIDS have developed innovative mechanisms such as the Technical Support Facilities which seek to develop alternative, local, and demand driven sources of technical assistance. While the fledgling Technical Support Facilities and other such efforts including indigenous community based organizations take off, the Global Fund will experience considerable frustration over the issue of acquiring sufficient technical assistance to utilize the funds disbursed.

Whether this necessarily implies a need for the Global Fund to set up its own technical assistance facility however, remains unclear. To set up such a facility will require considerable expansion of the Global Fund's mandate and operations. If this does draw the organization away from addressing its core function - to allocate and distribute financial resources quickly — its commitment to responding to country-led demands will be undermined - in particular if it imposes its own technical assistance facility on countries. Given the importance of political and advocacy skills in unblocking some of the severest bottlenecks in countries, the Global Fund's efforts may be better placed in 
strengthening its leadership and relationships at the country level. Answering the question of how best to ensure appropriate technical support to facilitate the movement of funds requires new and different relationships between the Global Fund and political and civil service officials, United Nations partners, civil society and the wide range of other actors with in-country presence and experience.

\section{SHOULD THE GLOBAL FUND EXPEND ITS ENERGIES MORE BROADLY IN STRENGTHENING HEALTH SYSTEMS IN COUNTRIES?}

While the Global Fund has recognized that the strength of health systems is integral to the impact of most, if not all, health interventions, health systems strengthening was not a key priority in its early years. Although systems strengthening was never excluded as an area of funding, it was only in the fifth round of requests for proposals that the Global Fund included a fourth explicit cross-cutting category of 'Health System Strengthening'. This reflects the ongoing discourse within the Global Fund - whether the Global Fund should develop this as a fully fledged separate category for funding, whether it should form a part of other categories for funding, or whether the Global Fund should seek to strengthen the capacity of other agencies already involved in health systems strengthening?

The Global Fund will need to consider its options carefully. Working with other agencies may be frustrating and may not yield sufficiently quick results. Addressing the issue as a part of other categories of funding may also not yield results that are substantial. Developing health systems strengthening as a separate category will, however, require significant reorganization within the Global Fund.

The proposals received for the fifth round reveal that countries are not clear about the extent of what is to be included in health systems strengthening and neither was the Global Fund able to help countries to define their proposals more carefully. ${ }^{8}$ The Global Fund's own expert review panel has pointed out that 'the Global Fund's system is not currently set up to generate strong Health System Strengthening proposals nor to evaluate these effectively'. ${ }^{9}$ Moreover, however effective the Global Fund Technical Review Panel is for intervention projects, it will be difficult to constitute a global-level panel of experts that is able to assess and support system-wide interventions for which country level political and institutional appraisal is critical.

\section{HOW TO CONTINUE EFFECTIVELY WITH PERFORMANCE-BASED FUNDING?}

While performance-based funding is now becoming a mainstream requirement for various agencies in the global health environment, the Global Fund, mainly to its credit, has rigorously and regularly exercised this approach. Its refusal in a number of cases to disburse second tranche releases due to failure to meet the required measures (e.g. Senegal), or to suspend grants due to inadequate fiduciary performance (e.g. Uganda), has sent a strong message to recipients. This has gone a long way towards building credibility with donors.

Two things however should be addressed in the immediate future. First, the Global Fund needs to quickly address the concerns voiced by countries that performancebased funding is a punitive mechanism. Not only is this damaging to the reputation of the Global Fund in countries, it does not make good money sense where it is the case. In the business sector, important investments are not withdrawn without an extensive analysis of the various factors affecting performance and giving the investment adequate time to perform.

In an effort to move towards greater grant optimization, the Global Fund has already partly sought to strengthen its performance measurement systems, introducing site verifications of results for all grants in 2006 and data quality assessments and audits by the end of 2007. The Global Fund, however, needs to engage in more sophisticated risk assessment of the environments that it engages with, accounting for the many intangible but real obstacles to implementation such as systemic and political bottlenecks and adjust its requirements for performance accordingly. A transparent, adjusted performance-based funding system is likely to increase the credibility of the Global Fund with governments and civil society as well as bringing the best returns for its investments.

Second, the Global Fund should attempt to design a framework and the necessary performance metrics to evaluate its own performance. Measurement must be stretched beyond whether the grants are not allocated and disbursed quickly, to whether they are easily and equitably accessible to all groups at the country level and whether they contribute to country-level capacity building and sustainable action in countries. An effort to exercise mutual accountability will be appreciated by donors and countries alike, making it much easier for the Global Fund to rationalize performance-based funding in countries and also to press donors to give more.

\section{CONCLUSIONS}

The world will watch anxiously as the Global Fund grapples with how to move from start up to the next stage in its organizational development-particularly in light of the trajectory of these epidemics. How it will address them will hinge in large measure on the qualities of its incoming Director. Although changes are expected, the Global Fund will do well not to change some of the attributes that have distinguished it thus far. In the coming years, its most 
effective stance will still be a focused agenda for raising and spending funds for AIDS, tuberculosis and malaria.

There are however things that will need to be done differently, especially if it is to take on the role of being one of the principle drivers of the Universal Access process. Two key efforts are especially critical: First, to improve upon the size and effectiveness of funds flowing through the Global Fund, its new leadership will need to move beyond simple resource mobilization and disbursement, to leveraging the organization's tremendous influence and to create a space for greater harmonization and alignment in accordance with national plans and priorities and the many, innovative efforts of its partners at the global and country levels. Such an effort will be invaluable in moving towards building local capacity for technical assistance and health systems strengthening. In so doing, the Global Fund will be a much needed example of a development organization that has not gone down the well trodden path of setting up its own agencies in countering the bottlenecks faced in implementation.

Second, to ensure its long term credibility, the Global Fund will need to ensure that countries not only become more engaged in mobilizing and committing their own funds and in voicing their demand for additional resources, they also need to become more actively involved in holding the Global Fund accountable for its efforts. While much of the emphasis has been on speed and transparency, it will be important in the coming years for the Global Fund grants to demonstrate sustainability of their efforts in countries and reduced transaction costs - particularly for recipients. The Global Fund must seek to foster an environment and procedures for public and mutual accountability, involving North and South, non-state and parliamentary actors.

It is with these key efforts to ensure the credibility of the organization and the sustainability and effectiveness of funds spent that the Global Fund will continue along its trajectory as a path-breaking financing mechanism to tackle these preventable diseases associated with poverty.

Disclaimer The views expressed in this article do not represent the views of UNAIDS.

Competing interests None declared.

\section{REFERENCES}

1 The Global Fund spending accounts for $21 \%$ of international spending on HIV and AIDS, $64 \%$ on Malaria and $67 \%$ on tuberculosis. (Global Fund, Funding the Global Fight Against HIV/AIDS, Tuberculosis and Malaria, Resource Needs for the Global Fund 2006-2007, 2008-2009, June 2006, p.12).

2 Between 2001 and 2006, the Global Fund has signed grant agreements worth US\$4 billion for 333 grants in 127 countries. In just over three years, the Global Fund has disbursed US\$2.26 billion to grant recipients. (Global Fund, Investing in Impact-Mid-Year Results Report 2006, June 2006, Executive Summary)

3 Country level consultations on universal access were held in over 130 countries and regional level consultations occurred in 7 regions in the first months of 2006. The UNAIDS Secretariat also convened a multipartner Global Steering Committee which met three times to identify global-level actions, to provide insights and inspiration, and to act as a political sounding board (See UNAIDS, Towards universal access UNAIDS assessment on scaling up HIV prevention, treatment, care and support, 2006).

4 UNAIDS, Towards universal access UNAIDS assessment on scaling up HIV prevention, treatment, care and support, 2006

5 Global Fund, Funding the Global Fight Against HIV/AIDS, Tuberculosis and Malaria, Resource Needs for the Global Fund 2006-2007, 2008-2009, June 2006 , p. 5.

6 See http://www.joinred.com/ and http://www.theglobalfund.org/ en/partners/private/red/ for more details on the Product Red effort.

7 Pettifor, A, Barwa, C, Zeitz, P. Global Fund Debt Conversion Report, A joint Report from Advocacy International and the Global AIDS Alliance, July, 2005.

8 Shakow, A. Global Fund-World Bank HIV/AIDS Programs, Comparative Advantage Study, January 2006.

9 Global Fund, Report of the Technical Review Panel and Secretariat, 11th Board Meeting, pp. 23-25. TRP 